\title{
The Future of Social Learning: A Novel Approach to Connectivism
}

\author{
Holm Smidt \\ University of Hawai'i at Mānoa \\ hsmidt@hawaii.edu
}

\author{
Matsu Thornton \\ University of Hawai'i at Mānoa \\ matsut@hawaii.edu
}

\author{
Kaveh Abhari \\ University of Hawai ‘i at Mānoa \\ abhari@hawaii.edu
}

\begin{abstract}
The primary goal of this paper is to operationalize the connectivism approach into a new learning model with additions from problem-based and contextual learning that can be effectively implemented together, to improve socioeconomically diverse learners' educational outcomes (attitude and persistence) in STEM (Science, Technology, Education and Mathematics) areas. We model this approach through the development and demonstration of an innovative, evidence-based, and scalable how-to-learn program that leverages connectivism principles and technology. This paper uses the case of energy education to provide contextual relevancy and prepare learners for the high demand jobs of the future. The new model is developed within the context of Internet of Things (IoT), where students have a unique opportunity to participate in a real-world application of an IoT system for green energy governance.
\end{abstract}

\section{Introduction}

The connectivism approach, a promising new strategy for the digital age, explains how self-regulated learning occurs in an increasingly connected world $[12,13,39]$. Connectivism acknowledges that learning rests in a diversity of opinions, cannot be taken for granted, and can be acquired in many different ways beyond formal educational settings. As a pedagogical lens, connectivism builds on the principles of constructivism to realize the teaching and learning potential of digital technology $[4,5,25,41]$.

Much of the literature on connectivism has focused on higher education (where it originated) because student agency (learning autonomy), and connectivity (learning network) are easier to implement in higher education settings where there is improved selfregulation and motivation. Few empirical studies have explored the value of this approach among middle school students in formal education settings. Additionally, there is still insufficient research regarding optimal applications of social technologies in inclusive K-12 environments [5,34]. Existing connectivist models for K-12 focus on fixed exploration opportunities (information seeking) for students without a systematic approach for directing interactive learning [48]. Moreover, the value of knowledge accumulation is inappropriately emphasized relative to the self-directed problem-solving necessary for success in the STEM fields of the $21^{\text {st }}$ century [38]. Although some researchers acknowledge the necessity of systematic approaches to connected learning in $\mathrm{K}-12$, to our knowledge, they do not provide a roadmap to implement and test connectivism beyond information seeking.

To address these limitations, this paper operationalizes connectivism principles into an actionable framework (learning model) with inclusion of problem-based learning (PBL) and contextual learning. We develop an instructional model to address the connectivism limitations in STEM education by answering questions of 'how to learn', 'what to learn' and 'why to learn'. Then, we offer educators and researchers a case for design and implementation in a contextually relevant setting, green energy governance.

\section{Literature review}

The development of technology is outpacing the current educational system's ability to develop an established curriculum as the developments occur. Siemens explained that learning is a process of connecting information sources [39]. Given the exponential growth of information availability, he maintained that modern approaches to learning should provide new possibilities for students to communicate in networks, and to aggregate varied information streams. In order to learn effectively in today's developing technological environment, students must be able to find the information that is needed quickly and assimilate new ideas and skills as they become not only available but also germane to the tasks at hand. The resources available are wide and varied and becoming even more so as time passes. Very often what spells 
success in modern frameworks is not the ability to memorize or even apply skills trained for, but to be able to find the pertinent information quickly, incorporate it into a personalized skillset, then apply and refine [27]. Connectivism places networked or social learning at the core of instruction and addresses the described needs for effective learning [13].

The connectivism approach has commonalities with constructivism and active learning theory, which share the core proposition that each learner needs to construct his or her own mental models in an individualistic way through real-life experiential learning [14,40]. The foundations of connectivism apply the principles of constructivism to informal, networked, technologysupported arenas in which networked learning can serve as a foundation of the learning processes [42].

According to Siemens's, connectivism learning is facilitated when connections are made between ideas in learning networks, which are composed of numerous information resources and technologies [39]. Siemens further argued that knowledge resides in a distributed manner across a sociotechnical network and learning is the act of recognizing patterns within complex information network [40]. It is assumed by connectivists that information is plentiful and available; therefore, the learner's role is not to memorize, but to find, process, and apply knowledge when and where it is needed [1].

Although some scholars believe that connectivism is not a new theory of learning but rather a pedagogical approach [22], it is well accepted that it at least connects existing theories and builds on them by incorporating social technology to advance education $[6,19,26]$. Connectivism guides the formulation of different webbased instructional methodologies such as using social media for informal learning [4,5]. Previous studies show that social technology can be used in different ways to support the connectivist approach and enhance the quality of learning in areas which show a trend for not being well understood [7,31].

Implications of the connectivist pedagogy for online learning environments have also extended to K-12 education models [20]. It is argued that a connectivist approach to K-12 instructional design should promote access, critical evaluation, and synthesis of concepts, opinions and perspectives that are embedded in diverse nodes across social learning networks $[10,15]$. Quinton and Allen further stated the need for new thinking, where the focus is not just on what to learn, but also the context-driven methods and tools that enhance the student's learning capacity [33].

Connectivism has a clear applied solution in terms of 'process' (employing social technologies to promote networked or social learning); however, the approach by itself falls short for the formation and distribution of 'content' (knowledge) in a networked world [6]. Self- regulated learning is a necessary component of operationalization of connectivism principles. Context has been recognized as having a fundamental influence on self-regulated learning since its formal conceptualization [32]. While connectivism is a useful lens, it treats 'technology' as a culture-free black box. Its premise is that social technologies enable learning. However, a more accurate statement would be that social technologies aligned with learners' needs, values, and contexts can assist learning. Further investigations are therefore necessary to explain how connectivist principles for social learning can be integrated into a framework that can be implemented in K-12 STEM environments where self-regulated learning can generally not be assumed.

\section{Model development}

We explore different areas of learning process, learning content, and learning environment in grades 68 in STEM education by developing a framework that instructs on how to learn, what to learn, and why to learn. The pedagogical perspective of connectivism builds on social learning models which examine learning through social networks $[2,17]$. To narrow the gap between conceptual online learning models and actionable connectivism-based learning frameworks, we focus on operationalizing four principles of connectivism as proposed by Downes: learner agency, resource openness, network connectivity, and opinion diversity [12]. To leverage the aforementioned principles in a typical middle and high school educational setting to teach content that would otherwise be difficult to learn (i.e. STEM content), the missing element of guidance needs to be supplemented to the connectivism approach. The developed model hence expands on connectivism through integration of PBL strategies that address the question of what to learn. Lastly, a contextual learning approach is taken in answering the most important question of why students would be encouraged to learn through this model. Responding to these three critical questions led us to expand upon the connectivism approach. Figure 1 illustrates the synergy of the three approaches to learning process, content, and context. 


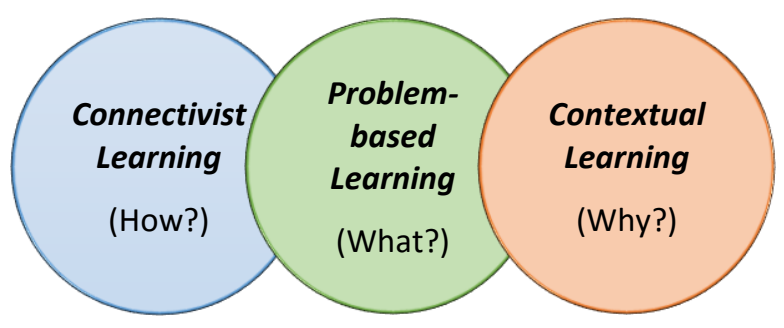

Figure 1: Three pillars of proposed learning model

\subsection{How to learn}

The learning process entails four operationalization strategies that support the learning process in networked learning environments.

3.1.1. Strategy I: Agency. The idea of agency or autonomy is identified with concepts of choice, expression of the self, control, and independence. An autonomous learning environment refers to one where students are expected to choose among resources, connections, and information to improve learning $[9,23,28]$. The ability to learn independently and select levels of choice/control has not been studied well in the K-8 connectivist learning literature. Previous research explored the concept of agency by minimizing traditional instructional processes and power structures (e.g. allowing students to choose learning materials and resources). However, the concept can go beyond that by allowing students to freely define the learning goals and outcomes. Learning agency is operationalized in this program by granting students authority to define their interests (what to learn) and choose learning tasks and resources (how to learn). The case design provides students with a personalized aggregate of learning activities in the context of IoT for energy governance in classrooms, and students decide which learning tasks can satisfy their project requirements in terms of knowledge/experience acquisition and contribution.

3.1.2. Strategy II: Openness. The connectivist notion of openness refers to open communication through networks to gain knowledge, share resources, ideas and expertise, and create new information and insights. Resource openness is operationalized by not only giving students access to a library of a variety of resources, but also guidance about how to build their own personal preferred library of resources for their individualized learning styles. An online learning library houses a collection of instructional lessons with various learning content that students can filter through and solve the problem they are tasked with. The platform also serves as the starting point for connectivist knowledge building as it hosts knowledge and points to other resources beyond the learning environment.

3.1.3. Strategy III: Connectivity. In networked learning environments, connectivity suggests encouraging students to take advantage of all the web has to offer, finding and elaborating connections among resources and seeking answers through discussion. Network connectivity is operationalized in the model by providing a platform for social interaction and resources that promote collaborative efforts beyond the classroom boundaries toward completion of project objectives. Additionally, students are encouraged to seek knowledge in their network of peers on the online platform, in their classrooms, and through their teachers. The connectivity of students on the platform allows students to build a class-, district-, and statewide learning community.

3.1.4. Strategy IV: Diversity. Emerging social learning networks enable students to seek different opinions and solutions by connecting to other learners and educators, both in and beyond the traditional classroom setting. Opinion diversity is operationalized by encouraging and promoting a range of perspective and approach in problem solving efforts where students with different cultural, social, and ethnic backgrounds can work towards a common goal. By connecting socioeconomically marginalized students from various classrooms, schools, and districts in the state, diversity can be actualized and promoted on the platform to aid in problem-solving. Students should be encouraged to take other students' opinions and priorities into account before formulating their solutions.

\subsection{What to learn}

Connectivism helps students systematically learn in middle to high school environments. To minimize this problem, we adapt the concept of PBL.

PBL creates a motivational setting through studentled learning and is oriented around an open-ended problem. Increased engagement through PBL strategies has been shown to improve achievement and selfefficacy among middle school students [24], as well as boost their intrinsic goal orientation, task value, use of elaboration learning strategies, critical thinking, and peer learning, when compared to non-PBL instruction [44]. Walker and Leary's [46] meta-analysis of 82 PBL studies and Springer et al.'s [43] meta-analytical study showed PBL in small groups supported high-need students' success in STEM fields. Gallagher and Gallagher [16] also reported that PBL instruction could surface students who had previously unseen academic potential, meaning the learning strategy not only 
benefits gifted and talented students, but also students whose full potential goes unrealized in traditional learning environments.

One critical reason for PBL's success in STEM education is that the situational interest aroused by the problem itself [37] not by the network or technology. As a results, the "problem" is "what" defines the STEM learning process not the connectivist principles. Therefore, we utilize the PBL process in our proposed framework to tailor the learning process for STEM education. The students will use real STEM cases situated in their own classrooms or community to encourage self-directed learning, leading to group discussions and refinement of ideas.

\subsection{Why to learn}

Connectivism largely treats technology as a tool independent from its context and its users. To build upon connectivism, we need to add contextual relevancy of content and technology. Contextually responsive instruction informs why to learn. It helps students to see the immediate value in learning in relationship with their environment. Contextually responsive strategies are based on the philosophy that students learn better when material is personally, historically, culturally, and geographically relevant. The concept is related to contextual learning, place-based education and environmental education [18]. Contextually responsive PBL can address achievement gaps by valuing diversity (cultural, racial, ability level, etc.) as a source of knowledge contributing to personal and social development [36]. Emphasizing personal relevance can also improve information retention. A meta-analysis of 126 studies on the self-reference effect suggests that contextual relevancy has a direct impact on students' learning outcomes [45]. Moreover, in typical classroom settings, at-risk and minority students can be marginalized; a contextually responsive approach on the other hand, values their diversity. Using the students' classroom climate as the contextual setting and mathematics in real-life contexts, this approach is expected to positively affect students' attitudes and instill feelings of being a successful STEM student as part of their personal identity [8,30].

\section{Sample course design}

In developing the new model, we emphasize connectivism's potential to reach learners who typically lack interest and self-confidence in STEM. The proposed strategies build on an existing social learning model and platform funded by the U.S. Department of Education to improve 8th-grade mathematics learning behavior, skills, and outcomes. The model develops and tests the effects of socially and culturally responsive problem-based learning strategies supported by (a) ongoing professional development for mathematics teachers and (b) an accessible online collaborative learning network for students.

This existing model is undergirded by research in connectivism, PBL, and contextually responsive education to improve inclusive pedagogy and technology integration with diverse learners in highneed Hawai'i schools, including students with disabilities and those placed in special needs classrooms. The mathematics materials developed are compatible with Common Core and national mathematics standards, while being culturally relevant to Hawai'i locals and Pacific Islanders, as evidenced in the titles of the first two volumes: Let's Build a Canoe and Let's Play the Ukulele. Teachers can opt to use printed materials (Student Worksheets and Teacher Notes) and/or the online learning platform. The project website includes professional development tools for teachers and supplemental videos and audio recordings for students, in addition to the interactive lesson modules and student forums.

In year two of the project, the pilot implementation included six underperforming Hawai' $i$ schools, 16 teachers and more than 500 students. At the conclusion of the pilot, the immediate results showed about 20 percent improvement in the grades of participating students when compared with the control group. Notably, 40 percent of participating students had one letter grade improvement from 7 th grade to 8th grade. Stakeholder teachers have been actively engaged in providing feedback regarding the content, compatibility, and implementation of the mathematics materials, reporting that students are more actively engaged with the locally relevant and technologyintegrated content.

Building on this project, the framework is operationalized into an actionable case design as illustrated in Figure 2. While the purpose and approach (first and second layer of Figure 2) were discussed in the model development section, the remainder of this paper discusses the implementation of each approach (third layer).

The following is a typical scenario of the proposed implementation in the context of energy education at the classroom level. A classroom will receive an IoT device kit. Each IoT device kit will contain several sets of parts. Each set will contain the pieces for a specific sensor/actuator, guidance for assembly, and guidance on the component's utility. Hardware (and guidance thereof) would be designed such that the assembly and installation will provide students with tasks that inspire collaboration and are challenging yet within their capabilities. Each group in the classroom would be able 
to solve real-world problems by assembling, testing, installing, and then viewing their device data feed on the online platform as they explore their open-ended tasks.

Provided with a library of resources and tools for collaboration on the online platform, students would learn to: (a) find information for hands-on assembly and installation of IoT devices; (b) agglomerate and visualize data for student-initiated reasoning on local energy challenges with the aid of mathematics and data science; (b) simulate, and examine different strategies for reduced energy consumption and improved classroom comfort; (c) discuss and collaborate on strategies using the online platform. This process will encourage a sense of collaborative achievement across the schools in the state of Hawai'i.

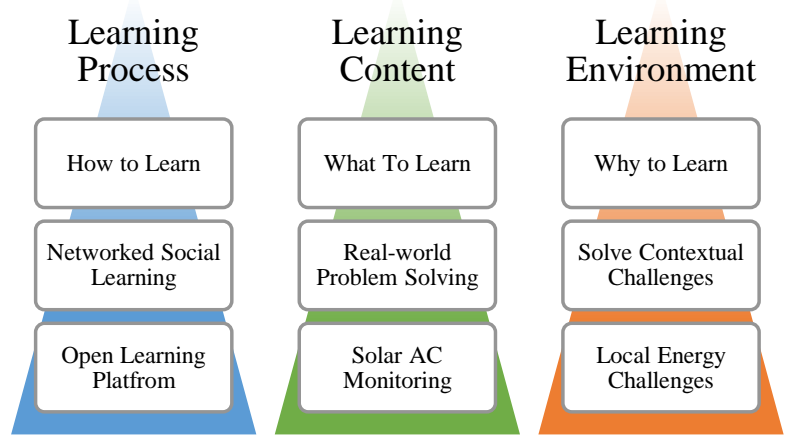

Figure 2: Implementation of the three pillars of the proposed learning model.

\subsection{Context: energy education}

This model has been developed in Hawai'i. Hawai'i is an ideal setting to study such a conceptual model with its unique cultural diversity, dire need for improvements in STEM education [30], and its unique position to pilot renewable energy projects. Hawaii's abundance of renewable energy resources, closed power grid system, and the State's goal of having $40 \%$ renewable energy by 2030 and 100\% renewable energy by 2045 (HB623) [49] motivate the design of innovative renewable energy projects at the University of Hawai' $i$, College of Engineering Renewable Energy Design Laboratory [29,35].

Further, the Hawai'i Department of Education has taken initiative through the Hawai'i Department of Education Heat Abatement Initiative (Act 47, SB3126) to improve school climates, which includes, in parts, to install solar powered AC in their classrooms [50]. Helping students to actively partake in improving their classroom climates, the energy education provides a contextually responsive framework for students to get engaged in STEM activities with direct personal impact. By starting with the seed of curiosity about energy and environment, the program focuses on learning that is "lifelong," "lifewide" and "life-deep" [3].

\subsection{Integration of mathematics curriculum with energy education}

High school mathematics is a primary gateway that has a direct effect on the students pursuing STEM education; yet, across the nation, $40 \%$ of students are falling behind in high school mathematics due to poor preparation in middle school mathematics $[11,47]$. The sample course design thus leverages the connectivist learning process in integrating mathematical concepts to the learning content.

Giving students access to the collective pool of data of all schools, students can learn about the application of probability, central tendencies, variability, and trends (Common Core State Standard 6.SP.A, 6.SP.B, 7.SP.B, and 8.SP.A) in evaluating the different strategies in reducing energy consumption and improving classroom climates. In Hawai' $i$, many 8th-grade students cover statistics in the last unit of their standardized GO Math! textbooks, when teachers are preparing for their end-ofthe-year standardized tests, the learning activities will foreshadow and supplement the statistical content that teachers usually run out of time to cover properly.

Analogous to the integration of culturally relevant mathematics material in the baseline project, we embed mathematical concepts in the context of a real-world IoT energy governance project in the classroom, thus giving students a contextual motivation for exploring the learning content.

\subsection{Data science and visualization}

In the context of visualizing energy consumption and classroom temperatures, students are given the opportunity to learn how to use an open source data analysis tool; the $\mathrm{R}$ statistical program. Self-guided student activities for learning $\mathrm{R}$ programming (mainly data visualization) are unique to this project, as activities are implemented in Swirl. Swirl is an open-source, free, and interactive learning platform used in classrooms around the world to simultaneously learn (and teach) the $\mathrm{R}$ programming language and data science. Using the Swirlify toolbox, custom teaching modules introduce $8^{\text {th }}$ graders to data science (and aforementioned mathematical concepts), guide them in their analysis and visualization by means of step-by-step instructions, and potentially excite their interest in data science. As Swirl modules teach the students at the command line interface, students are given full agency to choose which aspects of R they are interested in, when they want to go through learning modules, and at what pace. 
Given the project-based energy context, a data science activity (implemented in Swirl and made available on the online platform) may be integrated in the form of the algorithm shown in Listing 1. Students would learn how to access, process, and visualize the data with the goal of initiating (or validating) their optimization strategies. Using the interactive Swirl environment allows $8^{\text {th }}$-grade students with little to no programming experience to implement this complex algorithm and discuss the meaning of the results with their peers from the classroom and social network. This sample thus demonstrates how connectivism principles of agency and resource openness support the student learning process in a contextual and problem based setting.

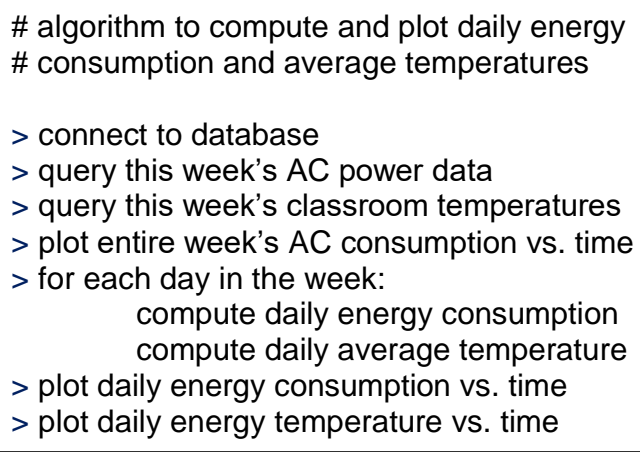

Listing 1: Sample algorithm for $8^{\text {th }}$-grade students to implement in Swirl.

\subsection{Internet of Things integration with energy education}

Gartner predicts that by 2020 there will be 25 billion smart devices connected to the Internet. This \$22 trillion industry is growing exponentially with many applications in the development of smart systems such as smart grid, smart city, and smart farming. While the IoT application in energy has the compound annual growth rate of $24 \%$, according to Upwork in 2016, businesses are prevented from implementing IoT because of a lack of employees with the experience needed to build, use, and troubleshoot them. The demand for future professionals drives the need to integrate IoT science with STEM education.

4.4.1. Hardware device integration. Devices capable of collecting and reporting live power consumption data and exerting remote control over $\mathrm{AC}$ units are provided in educational kits to classrooms for installation with AC units (Figure 3). A series of open-ended activities are designed to create an interactive context to work in a real-world high-tech project. The activities include assembling an IoT device, measuring energy consumption in their schools, optimizing the solar AC settings, aggregating the data and reporting on the energy consumption patterns and ways to improve to fellow peers in their class, school, and online community.

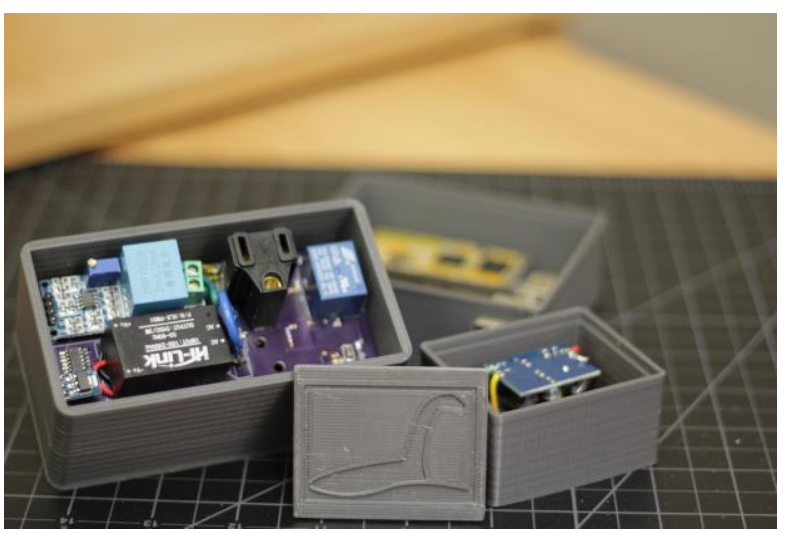

Figure 3: Sample loT hardware devices modeled for students.

Inquiry oriented instructions are made available through the online learning environment. Resource openness ensures that students have the opportunity to choose how to learn, when to learn, and from whom to learn. In order to assemble and install IoT devices, (such as shown in Figure 4), students need to go through learning modules, connect to peers and mentors through forums, or directly seek knowledge from University mentors (e.g. through forums). Through collaboration with research entities at the University, students have access to state of the art technology devices to nurture perception of and persistence in STEM.

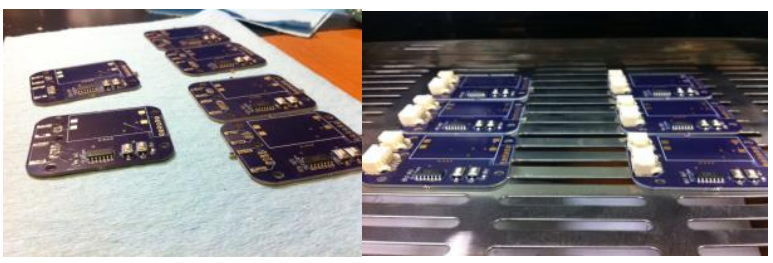

Figure 4: loT hardware assembly in classroom.

4.4.2. Front-end dashboard for user interaction. Interactive front-end dashboards provide visualization and control of their hardware installations out of the box, shown in Figure 5. The use of interactive dashboards allows students to comprehend the relation between various system components, as well as how control parameters (i.e. temperature) effect energy consumption or how solar cloud coverage can affect power production of solar panels. A steep learning curve and quick successes encourage students to access resources and stay active in the social learning network 
to share with their peers. Customization of these dashboard and learning tools is encouraged and operationalized through inquiry oriented instructions.

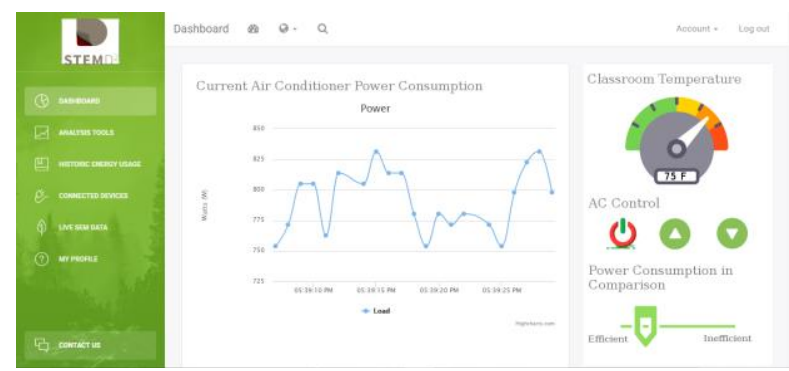

Figure 5: Customized dashboard by students for solar AC energy monitoring in classroom.

\subsection{Implementation platform and operationalization}

A custom developed social learning platform is used to operationalize the connectivism-based learning process (i.e. four connectivism principles) in a learning environment that spurs and empowers student learning. The key elements of the learning environment are as follows: (a) social network aspects (e.g. student profile, friends, groups, etc.); (b) a learning library (e.g. learning activities, articles, references to other tools, etc.); (c) a forum for sharing ideas, asking questions, and presenting their results to peers and mentors; (d) a teacher's corner for professional development and implementation guidance.

4.5.1. Operationalizing connectivist principles. The social network features allow students to interact with the networked learning environment and access all its resources. The learning library is of integral importance to operationalizing resource openness and student agency. Students are not bound to limited information. They are free to explore and choose which learning tools to use. Ultimately, students can create a personalized learning library (e.g. specific Swirl modules, certain interactive learning modules on IoT hardware, hands-on tutorials, device documentations, etc.) by bookmarking resources on the learning environment. Opinion diversity is operationalized through the forums on the online platform. Students are not only encouraged to seek information and opinions in the forums, but are foremost asked to showcase their own work. With a diversity of groups approaching the same tasks, one might expect that they run into similar problems. The same holds true in industry. There are any number of examples of online forums where professionals go to find what their peers have done when facing problems similar to their own. With a diversity of students, we expect a diversity of approaches and solutions which can be shared freely among peers. The contextual learning content lies in the connections between resources from the learning library, external resources, and forum discussions that mimic a real-world situation where students need to either locate information themselves or ask people who may know the answer or have a different optimization solution. The learning process therefore necessitates that students learn how to access, connect, and use these vast resources for solving green energy governance problems.

4.5.2. Professional development in energy education. We recognize that the success of such a framework in the context of mathematics hinges upon the collaboration with and implementation by school teachers. Comprehensive and sustainable teacher professional development must be provided to help teachers develop competency, confidence, and commitment in implementing both connectivism principles (i.e. learning process) and the learning content.

Participating teachers learn about connectivism and the logic behind each connectivist strategy (agency, openness, connectivity, and diversity). The synergetic effects of the four connectivist principles can change the role of teachers from instructors to resource integrators who orchestrate a learning network, teach how to learn and share in the network, and empower students to reveal their true learning identities and preferences.

A teacher training station serves to familiarize teachers with the energy context. The teacher station entails a fully functional IoT hardware installation display and hardware assembly station. Workshops are performed at the station for the implementation of the specifically designed and $8^{\text {th }}$-grade tailored IoT hardware kits and data science analysis tools. The training station goes beyond providing teachers hands on training in the analysis and hardware installations to potentially aid students in their learning process. It also serves as an educational and demonstration tool to show the teachers (and interested students) what is happening at the forefront of research in renewable energy, smart grid, IoT sensor networks, and data science.

All teacher education content is accessible through the teacher's corner on the learning platform. Teachers can access content in the form of learning activities, videos, and documents, and conveniently connect to other teachers and mentors through the teachers' forum. The teacher education thus provides the means to establish an optimal classroom setting for the implementation of connectivist and PBL strategies.

\section{Expected outcomes \& future study}


This paper reviews the transformative concept of connectivism with additions and suggests a new alternative strategy to support STEM learning processes. The proposed strategy enabled by social technologies narrows the opportunity and achievement gaps for all learners including diverse learners traditionally marginalized in STEM education. Contributing to the call for further research on the application of connectivism in education [5], the proposed strategy could direct further research and investment in social learning technologies.

This paper advances knowledge on the understanding of connectivism and its limitations. We argued that connectivism treats 'technology' as a culture-free black box with a premise that social technologies enable learning. Then, we tried to improve this approach by providing a mechanism to align social technologies with learners' needs, values, and contexts to assist learning. It adds to the theoretical framing of connectivism by emphasizing the contingencies of technology's influence on learners. This paper also contributes to practice by setting a model to test the effectiveness of the proposed model in improving student-learning outcomes. Educators can adapt the model for contexts other than energy education to provide an effective approach to engaging and supporting marginalized students to build selfconfidence and interest in STEM.

\section{Acknowledgements}

This research is made possible by the support of the U.S. Department of Education, Native Hawaiian Education Act Program (Award \# S362A140018).

\section{References}

[1] Anderson, T. and Dron, J. Three generations of education pedagogy. International Review of Research in Open and Distance Learning 12.3, March (2011), 80-97.

[2] Banati, H. and Arora, N. Enabling inclusive education in structured learning environments through social network analysis. International Journal of Innovation in Education 2, 2-4 (2014), 151-167.

[3] Banks, J.A. Learning in and out of school in diverse environments: Life-long, life-wide, life-deep. LIFE Center, University of Washington, Stanford University, and SRI International, 2007.

[4] Barnett, J., McPherson, V., and Sandieson, R.M. Connected teaching and learning: The uses and implications of connectivism in an online class. Australasian Journal of Educational Technology 29, 5 (2013), 685-698.

[5] Bell, F. Network theories for technology-enabled learning and social change: Connectivism and actor network theory. 7th International Conference on Networked Learning, (2010), 526-533.

[6] Bell, F. Connectivism: Its place in Theory-informed research and innovation in technology-enabled learning. International Review of Research in Open and Distance Learning 12, 3 (2011), 98-118.

[7] Blanco-Fernández, Y., López-Nores, M., Pazos-Arias, J.J., Gil-Solla, A., Ramos-Cabrer, M., and Garc'lia-Duque, J. REENACT: A step forward in immersive learning about Human History by augmented reality, role playing and social networking. Expert Systems with Applications 41, 10 (2014), 4811-4828.

[8] Bonner, E.P. and Adams, T.L. Culturally responsive teaching in the context of mathematics: A grounded theory case study. Journal of Mathematics Teacher Education 15, 1 (2012), 25-38.

[9] Boud, D., ed. Developing Student Autonomy in Learning. Routledge, 2012.

[10] Couros, A. Open, connected, social - implications for educational design. Campus-Wide Information Systems 26, 3 (2009), 232-239.

[11] Darling, E.J.S. Access to Algebra I, Gateway to Success: The Impact of Eighth-Grade Algebra I. 2010. http://dc.etsu.edu/cgi/viewcontent.cgi?article=3069\& context $=$ etd.

[12] Downes, S. Connectivism and Connective Knowledge: essays on meaning and learning networks. 2012.

[13] Duke, B., Harper, G., and Johnston, M. Connectivism as a digital age learning theory. The International HETL Review, (2013), 4-13.

[14] Ertmer, P.A. and Newby, T.J. Behaviorism, Cognitivism, Constructivism: Comparing Critical Features from an Instructional Design Perspective. Performance Improvement Quarterly 6, 4 (1993), 50-72.

[15] Firdausiah Mansur, A.B. and Yusof, N. Social learning network analysis model to identify learning patterns using ontology clustering techniques and meaningful learning. Computers \& Education 63, (2013), 73-86.

[16] Gallagher, S.A. and James J. Gallagher. Using Problem-based Learning to Explore Unseen Academic Potential. Interdisciplinary Journal of Problem-Based Learning 7, 1 (2013).

[17] Greenhow, C. and Askari, E. Learning and teaching with social network sites: A decade of research in K-12 related education. Education and Information Technologies, (2015), $1-23$.

[18] Gruenewald, D.A. The best of both worlds: a critical pedagogy of place. Educational Researcher 32, 4 (2003), 3- 
12.

[19] Guder, C. Patrons and Pedagogy: A Look at the Theory of Connectivism. Public Services Quarterly 6, 1 (2010), 36-42.

[20] Hossain, M. and Wiest, L.R. Collaborative middle school geometry through blogs and other Web 2.0 technologies. Journal of Computers in Mathematics and Science Teaching 32, 3 (2013), 337-352.

[21] Hwang, G.-J., Sung, H.-Y., Hung, C.-M., and Huang, I. A Learning Style Perspective to Investigate the Necessity of Developing Adaptive Learning Systems. Educational Technology \& Society 16, 2 (2013), 188-197.

[22] Kop, R. and Hill, A. Connectivism: Learning theory of the future or vestige of the past? International Review of Research in Open and Distance Learning 9, 2008.

[23] Lerma, O. and Kreinovich, V. Student Autonomy Improves Learning: A Theoretical Justification of the Empirical Results. Uncertain Systems 10, 1 (2016), 34-38.

[24] Liu, M., Hsieh, P.P.-H., Cho, Y., and Schallert, D.L. Middle school students' self-efficacy, attitudes and achievement in a computer-enhanced problem-based learning environment. Journal of Interactive Learning Research 17, 3 (2006), 225-242.

[25] Mallon, M.N. Extending the Learning Process: Using the Theory of Connectivism to Inspire Student Collaboration. Kansas Library Association College and University Libraries Section Proceedings 3, 1 (2013), 18-27.

[26] Mattar, J. a. Constructivism and Connectivism in Education Technology: Active , Situated, Authentic, Experiential, and Anchored Learning. 2010.

[27] McLoughlin, C.E. The pedagogy of personalised learning: exemplars, MOOCS and related learning theories. Proceedings of EdMedia: World Conference on Educational Media and Technology 2013, Association for the Advancement of Computing in Education (AACE) (2013), 266-270.

[28] McLoughlin, C.E. and Lee, M.J.W. Personalised and self regulated learning in the Web 2 . 0 era: International exemplars of innovative pedagogy using social software. Australasian Journal of Educational Technology 26, 1 (2010), 28-43.

[29] Motalleb, M., Thornton, M., Reihani, E., and Ghorbani, R. Providing frequency regulation reserve services using demand response scheduling. Energy Conversion and Management 124, (2016), 439-452.

[30] National Center for Education. A First Look: 2013 Mathematics and Reading. The Nation's Report Card, (2013), $1-12$.

[31] Noteborn, G., Dailey-Hebert, A., Carbonell, K.B., and Gijselaers, W. Essential knowledge for academic performance: Educating in the virtual world to promote active learning. Teaching and Teacher Education 37, (2014), 217234.

[32] Pintrich, P.R. and de Groot, E. V. Motivational and self-regulated learning components of classroom academic performance. Journal of Educational Psychology 82, 1 (1990), $33-40$.

[33] Quinton, S.R. and Allen, M.M. The Social Processes of Web 2.0 Collaboration: Towards a New Model for Virtual Learning. Curriculum Models for the 21st Century, (2014), $35-53$.

[34] Redecker, C., Ala-mutka, K., and Punie, Y. Learning 2.0 - The Impact of Social Media on Learning in Europe. Learning 10, (2010), 17.

[35] Reihani, E., Motalleb, M., Thornton, M., and Ghorbani, R. A novel approach using flexible scheduling and aggregation to optimize demand response in the developing interactive grid market architecture. Applied Energy 183, (2016), 445-455.

[36] Schellenberg, R. and Grothaus, T. Using culturally competent responsive services to improve student achievement and behavior. Professional School Counseling 14, 3 (2011), 222-230.

[37] Schmidt, H.G., Rotgans, J.I., and Yew, E.H.J. The process of problem-based learning: what works and why. Medical Education 45, 8 (2011), 792-806.

[38] Shemwell, J.T., Gwarjanski, K.R., Capps, D.K., Avargil, S., and Meyer, J.L. Supporting Teachers to Attend to Generalisation in Science Classroom Argumentation. International Journal of Science Education 37, 4 (2015), 599628.

[39] Siemens, G. Connectivism: A learning theory for the digital age. International Journal of Instructional Technology and Distance Learning 2, 1 (2005), 3-10.

[40] Siemens, G. Connectivism : Learning and Knowledge Today. Global summit 2006 : technology connected futures, (2006).

[41] Siemens, G. Learning and Knowing in Networks: Changing roles for Educators and Designers. ITForum, 1 (2008), 1-20.

[42] Siemens, G. New structures of learning: The systemic impact of connective knowledge, connectivism, and networked learning. Universidade do Minho, 2008, 7-23. http://elearnspace.org/Articles/systemic_impact.htm.

[43] Springer, L., Stanne, M.E., and Donovan, S.S. Effects of Small-Group Learning on Undergraduates in Science, Mathematics, Engineering, and Technology: A MetaAnalysis. Review of Educational Research 69, 1 (1999), 2151. 
[44] Sungur, S. and Tekkaya, C. Effects of problem-based learning and traditional instruction on self-regulated learning. The journal of educational research 99, 5 (2006), 307-320.

[45] Symons, C.S. and Johnson, B.T. The self-reference effect in memory: a meta-analysis. Psychological bulletin 121, 3 (1997), 371.

[46] Walker, A. and Leary, H. A Problem Based Learning Meta Analysis: Diff erences Across Problem Types, Implementation Types, Disciplines, and Assessment Levels. Journal of problem-based learning 3, 1 (2009), 6-28.

[47] Walston, J. and McCarroll, J.C. Eighth-Grade Algebra: Findings From the Eighth-Grade Round of the Early Childhood Longitudinal Study, Kindergarten Class of 1998-
99 (ECLS-K). National Center for Education Statistics, 2010. http://nces.ed.gov/pubs2010/2010016.pdf.

[48] Williams, R., Karousou, R., and Mackness, J. Emergent Learning and Learning Ecologies in Web 2.0. The International Review of Research in Open and Distributed Learning 12, 3 (2011), 39-59.

[49] HB623 SD2 HD2 CD1. House of Representative, 28th Legislature, State of Hawaii, Honolulu, Hawaii.

[50] Act 47, SB3126 SD2 HD2 CD1. Governor of the State of Hawaii, Honolulu, Hawaii, 2016. 